\title{
Reduced capillary hydraulic conductivity in skeletal muscle and skin in Type I diabetes: a possible cause for reduced transcapillary fluid absorption during hypovolaemia
}

\author{
H. Olsen ${ }^{1}$, T. Länne ${ }^{2}$ \\ ${ }^{1}$ Department of Endocrinology, Lund University, Malmö University Hospital, Malmö, Sweden \\ ${ }^{2}$ Department of Vascular and Renal Diseases, Lund University, Malmö University Hospital, Malmö, Sweden
}

\begin{abstract}
Aims/hypothesis. Patients with Type I (insulin-dependent) diabetes mellitus have a reduced transcapillary fluid absorption from skeletal muscle and skin and thus defective plasma volume regulation during hypovolaemia. Our aim was to find whether a defective capillary filtration coefficient or impaired transcapillary driving force are aetiologic factors for this reduction.

Methods. We investigated 11 diabetic patients (diabetes duration $6.9 \pm 1.1$ years, age $26 \pm 1$ years), without complications and 12 control subjects ( $26 \pm 1$ years). Their capillary filtration coefficient was measured in the upper arm using a volumetric technique at rest and during lower body negative pressure (LBNP). We calculated the driving force for transcapillary fluid transfer.

Results. The increase in heart rate and the decrease in systolic blood pressure during lower body negative pressure were similar in diabetic and control subjects. The resting capillary filtration coefficient was
\end{abstract}

decreased in the diabetic subjects, $0.033 \pm 0.003$ vs $0.051 \pm 0.007 \mathrm{ml} \cdot 100 \mathrm{ml}^{-1} \cdot \mathrm{min}^{-1} \cdot \mathrm{mmHg}^{-1}$ $(p<0.05)$. During lower body negative pressure, the capillary filtration coefficient increased $35 \%$ in both groups compared with resting capillary filtration coefficient and was still decreased in diabetes; $0.046 \pm 0.004$ compared with $0.069 \pm 0.006 \mathrm{ml}$. $100 \mathrm{ml}^{-1} \cdot \mathrm{min}^{-1} \cdot \mathrm{mmHg}^{-1}(p<0.01)$. The established driving force during lower body negative pressure was $1.37 \pm 0.11$ vs $1.30 \pm 0.15 \mathrm{mmHg}$ (NS) in diabetic and control subjects, respectively.

Conclusions/interpretation. Our study indicates that a reduced capillary filtration coefficient rather than defective regulation of transcapillary driving force, is the reason for the reduced transcapillary fluid absorption during hypovolaemic circulatory stress found in Type I diabetic patients. [Diabetologia (2000) 43: 1178-1184]

Keywords LBNP, capillary filtration coefficient, sympathetic activation, diabetes mellitus, muscle
Patients with Type I (insulin-dependent) diabetes mellitus have a reduced transcapillary fluid absorption from skeletal muscle and skin to blood during hypovolaemic circulatory stress [1]. This fluid shift

Received: 28 January 2000 and in revised form: 8 May 2000

Corresponding author: H. Olsen MD, Department of Endocrinology, Malmö University Hospital, 20502 Malmö, Sweden Abbreviations: CFC, Capillary filtration coefficient; $\mathrm{CFC}_{\mathrm{LBNB}}$ capillary filtration coefficient during lower body negative pressure; DBP, diastolic blood pressure; LBNP, lower body negative pressure; MAP, mean arterial pressure; SBP, systolic blood pressure. has been shown to have a major effect on early plasma volume restitution during rapidly started hypovolaemic circulatory stress $[2,3]$. The fluid absorption is caused by a sympathetic $\alpha$-mediated and $\beta$-mediated decrease in capillary pressure and is enhanced by a concomitant increase in capillary surface area available for fluid transfer [3-5]. The reduction of this beneficial fluid absorption in diabetic patients might lead to reduced tolerance to hypovolaemia with an increased risk for complications in situations such as bleeding, rapid gastrointestinal fluid losses or burn injuries. The possible explanations for the reduced fluid absorption in diabetic patients are a decreased 
capillary hydraulic conductivity (capillary filtration coefficient; CFC) or defect reduction in capillary pressure. Skin capillary pressure has earlier been shown to be increased in diabetic patients [6]. Some studies have found unchanged and others increased CFC $[7,8,9]$. Differences in methodological design could be a reason for these contradictory reports if myogenic and venoarterial reflexes influence $\mathrm{CFC}$ [10,11].

The aim of our study was to find whether disturbances in capillary hydraulic conductivity (capillary filtration coefficient, CFC), or impaired sympathetic regulation of the driving force responsible for fluid transfer, are aetiologic factors for the reduction of transcapillary fluid absorption during the hypovolaemic circulatory stress seen in Type I diabetes [1].

\section{Subjects and methods}

The study was conducted on 11 men with Type I diabetes (mean age 26 years; range 20-32 years); BMI $21.7 \pm 0.7 \mathrm{~kg}$. $\mathrm{m}^{-2}$. All were being treated with insulin but no other longterm medication. The mean duration of diabetes for the group was 6.9 years; range $2-11$ years. They all had normal urinary albumin excretion and no signs of retinopathy. The patients received four doses of insulin a day and their $\mathrm{HbA}_{1 \mathrm{c}}$ was $8.4 \pm 0.4 \%$ (range $6.3-10.8 \%$; reference value $<5.3 \%$ ). The control subjects were 12 healthy male volunteers, without diabetes, hypertension or any other systemic disease (mean age 26 years; range $20-33$ years), BMI $22.6 \pm 0.8 \mathrm{~kg} \cdot \mathrm{m}^{-2}$. No subject was taking any other medication and all gave informed consent to the experiments which were approved by the ethics committee of Lund University, Sweden. Of the diabetic patients three and of the control subjects one were cigarette smokers. They were instructed not to smoke on the day of the investigation. One diabetic patient and one healthy volunteer participated in the earlier study on transcapillary fluid absorption during hypovolaemic circulatory stress [1].

The randomised experiments started $1 \mathrm{~h}$ after a regular meal in the morning or noon. The subjects were instructed to abstain from coffee or tea on the day of the investigation. All diabetic subjects had taken their usual insulin dose. Blood-glucose was measured at the start and at the termination of experiments (Medisense compagnion 2, Medisense, Cambridge, Mass., USA).

The experiments lasted $3 \mathrm{~h}$ and were carried out in a relaxed and quiet atmosphere at a temperature of 22-24 $\mathrm{C}^{\circ}$. The subjects were in a supine position with their legs enclosed in an airtight box up to the level of the iliac crest with a rubber seal fitted hermetically around the waist. The box was connected to a vacuum source (lower body negative pressure, LBNP) permitting stable negative pressure to be rapidly produced (within $5 \mathrm{~s}$ ). The negative pressure in the LBNP chamber was continuously measured by a manometer (DT-XX disposable transducer, Viggo Spectramed, Helsingborg, Sweden) and held constant by a rheostat. Lower body negative pressure is an established technique that causes a defined experimental hypovolemic circulatory stress with a concomitant sympathetic activation due to deactivation of central baroreceptors [12].

The CFC and blood volume capacitance responses in the upper arm were measured using a volumetric technique [3]. The air-filled plethysmographs we used were cylindrical, $8 \mathrm{~cm}$ long and made of $3.5 \mathrm{~mm}$ thick transparent plastic. Each subject rested his right arm at the level of his heart. A plethysmograph was placed on the upper arm and the proximal, middle and distal circumferences of the enclosed segment of the arm were measured and the volume calculated. The plethysmograph was then sealed hermetically against the skin of the right upper arm with the aid of an elastomer (Provil, Bayer Dental, Leverkusen, Germany). We took care to avoid venous stasis. Changes in tissue volume were measured with a piston recorder connected to the plethysmograph. The piston recorder was placed in an airtight plastic box, in which a defined and stable negative pressure could be applied and transmitted through the piston to the plethysmograph. Thus, this experimental setup allowed changes in tissue volume to be measured simultaneously with the application of negative pressure in the plethysmograph [3].

The CFC was calculated from the fluid filtration that follows a defined small $(1.5-1.6 \mathrm{mmHg})$ pressure decrease in the plethysmograph. The transmission of negative external pressure to the underlying tissue has previously been shown to be full without any difference in pressure transmission in relation to tissue depth [13]. Furthermore, no changes are seen in intravascular pressure, indicating the establishment of a transmural pressure gradient over the capillary walls that is defined by the applied external negative pressure. External negative pressure causes typical volume changes essentially analogous to those evoked by an increment in local venous pressure. After an initial increase in regional blood content there is a progressive slow increase in volume due to a net transfer of fluid from the intravascular to the extravascular space. Net fluid filtration and applied external negative pressure were used to define CFC.

$\mathrm{CFC}=\Delta \mathrm{V}_{\mathrm{f}} / \Delta \mathrm{P}_{\mathrm{c}}$

In this definition $\Delta \mathrm{V}_{\mathrm{f}}$ denotes the fluid filtration $(\mathrm{ml}$. $100 \mathrm{ml}^{-1} \cdot \mathrm{min}^{-1}$ ) and $\Delta \mathrm{P}_{\mathrm{c}}$ the applied external negative pressure $(\mathrm{mmHg})$. After $45 \mathrm{~min}$ of supine rest basal $\mathrm{CFC}\left(\mathrm{CFC}_{\mathrm{C}}\right)$ in the right upper arm was measured by the application of external negative pressure $(1.5-1.6 \mathrm{mmHg})$ in the plethysmograph for $5 \mathrm{~min}$. The fluid filtration was measured from 2 to $5 \mathrm{~min}$, at which time the capacitance response is terminated. After the discontinuation of negative pressure, arm volume gradually returned to baseline within $20 \mathrm{~min}$. After $30 \mathrm{~min}$, central hypovolemic circulatory stress with a concomitant sympathetic stimulation was instituted with the aid of LBNP $\left(60 \mathrm{~cm} \mathrm{H}_{2} 0\right)$, during which CFC $\left(\mathrm{CFC}_{\mathrm{LBNP}}\right)$ was measured in the arm [3]. The LBNP was applied when the upper arm volume was stable and was maintained for $13 \mathrm{~min}$. After $3 \mathrm{~min}$ of LBNP, external negative pressure $(1.5-1.6 \mathrm{mmHg})$ was applied in the plethysmograph around the arm for 5 min to measure $\mathrm{CFC}_{\mathrm{LBNP}}$. The LBNP was continued after the CFC manoeuvre for an additional 5 min now with atmospheric pressure in the arm plethysmograph and then discontinued. The change in the transcapillary fluid absorption slope created by the applied negative pressure in the plethysmograph was divided by the applied negative pressure in the plethysmograph and was taken as $\mathrm{CFC}_{\text {LBNP }}$ [3]. The transmural driving force was calculated from the fluid absorption curve after $\mathrm{CFC}_{\mathrm{LBNP}}$ divided by $\mathrm{CFC}_{\text {LBNP }}$ The capacitance response in the upper arm was measured from the rapid volume change between baseline volume both at onset and at cessation of LBNP and the mean value was taken as the prevailing capacitance response.

In the analysis of the tissue volume responses during rapidly started hypovolaemic circulatory stress, abrupt changes are considered to reflect alterations of regional blood volume, whereas gradual volume changes reflect net transcapillary 
fluid transfer. This interpretation of tissue volume changes has been validated with the aid of simultaneously measured blood and tissue volume changes in animals [14,15] and in man [16].

Arterial blood pressure was measured non-invasively in the left upper arm with a semi-automatic blood pressure device (Omron, model HEM-700C, Tokyo, Japan). Mean arterial pressure (MAP) was taken as the diastolic pressure $+1 / 3$ of the pulse pressure.

To define the hypovolaemic stimulus caused by LBNP, we calculated the blood pooling in the legs by means of strain gauge plethysmography applied at the maximum circumference of the calf, approximately $15 \mathrm{~cm}$ distal to the knee [17]. The LBNP evoked an initial rapid increase of leg volume (capacitance response) followed by a slower but continuous increase reflecting net transcapillary fluid transfer from blood to tissue. As the capacitance response ends within about $3 \mathrm{~min}$, the transcapillary fluid filtration was measured from the slope between 3 and $8 \mathrm{~min}$ [18]. The capacitance response was calculated from the volume increase at the onset of LBNP to the line defined from the filtration slope. Data are given with reference to soft tissue weight excluding bone. Bone is taken as $10 \%$ in the upper arm [19] and $13 \%$ in the calf [20].

The ECG signal, plethysmograph pressure, pressure in the LBNP chamber and the calf volume were registered, amplified (PC polygraph, Synetics Medical, Stockholm, Sweden) and collected with a computer program (Gastrosoft polygram, Synetics Medical, Stockholm, Sweden) on a personal computer (SPC 386, SPC Trading AB, Uppsala, Sweden).

Statistical analysis. Values are expressed as means \pm SEM. We calculated area under the curve (AUC) for the changes in heart rate and blood pressure. The significance of the difference between the two groups was tested by unpaired Student's $t$ test. We considered $p$ less than 0.05 to be statistically significant.

\section{Results}

The resting heart rate, systolic blood pressure (SBP), diastolic blood pressure (DBP) and mean arterial pressure (MAP) were similar in diabetic patients and control subjects (Table 1 ).

Blood-glucose was $12.5 \pm 1.6 \mathrm{mmol} \cdot \mathrm{l}^{-1}$ before the experiments and $10.4 \pm 1.4 \mathrm{mmol} \cdot \mathrm{l}^{-1}$ at termination of the experiments in the diabetic subjects.

The subjects generally tolerated the LBNP of $60 \mathrm{~cm} \mathrm{H}_{2} \mathrm{O}$ well. One control and one diabetic subject developed a more pronounced fall in systolic blood pressure, with a decrease in heart rate and concomitant dizziness. These experiments were promptly discontinued and the results were excluded from the calculations, thus from these two subjects only resting $\mathrm{CFC}$ is reported.

The capacitance response (pooling of blood) in the calf in diabetic and control subjects during LBNP was similar: $2.29 \pm 0.24$ compared with $2.11 \pm 0.22 \mathrm{ml}$ $\cdot 100 \mathrm{ml}^{-1}(\mathrm{NS})$. The transcapillary fluid filtration in the calf during LBNP was also equal in both groups: $0.076 \pm 0.011$ compared with $0.090 \pm 0.009 \mathrm{ml}$ $\cdot 100 \mathrm{ml}^{-1} \cdot \mathrm{min}^{-1}(\mathrm{NS})$.
Table 1. Resting heart rate, systolic blood pressure (SBP) diastolic blood pressure (DBP) in diabetic patients and control subjects

\begin{tabular}{lrrl}
\hline & Diabetic & Control & $p$ \\
\hline Resting heart rate $\left(\right.$ beats $\left.\mathrm{min}^{-1}\right)$ & $62 \pm 1$ & $58 \pm 3$ & NS \\
SBP $(\mathrm{mm} \mathrm{Hg})$ & $119 \pm 2$ & $118 \pm 2$ & NS \\
DBP $(\mathrm{mm} \mathrm{Hg})$ & $71 \pm 2$ & $68 \pm 2$ & NS \\
\hline
\end{tabular}

During hypovolaemic circulatory stress caused by LBNP, heart rate increased, SBP decreased and DBP (\% of resting values) was unchanged (Fig. 1). When LBNP was discontinued, all the haemodynamic variables rapidly returned to baseline level. No statistically significant differences in changes in heart rate, SBP and DBP were seen between control and diabetic subjects in absolute or in relative values.

Figure 2 (left) shows an original tracing of volume changes in the upper arm of a 23-year-old diabetic patient during application of $1.5 \mathrm{mmHg}$ negative pressure in the arm plethysmograph. The continuous slow increase in volume represents capillary filtration from blood to tissue and was used to calculate the capillary filtration coefficient at rest $\left(\mathrm{CFC}_{\mathrm{C}}\right.$; see Methods). The $\mathrm{CFC}_{\mathrm{C}}$ was $0.035 \mathrm{ml} \cdot 100 \mathrm{ml}^{-1} \cdot \mathrm{min}^{-1}$. $\mathrm{mmHg}^{-1}$. Figure 2 (right) shows an original recording of CFC during the LBNP of $60 \mathrm{~cm} \mathrm{H}_{2} \mathrm{O}\left(\mathrm{CFC}_{\mathrm{LBNP}}\right)$ in the same 23-year-old diabetic patient. The $\mathrm{CFC}_{\mathrm{LBNP}}$ was $0.041 \mathrm{ml} \cdot 100 \mathrm{ml}^{-1} \cdot \mathrm{min}^{-1} \cdot \mathrm{mmHg}^{-1}$, that is $20 \%$

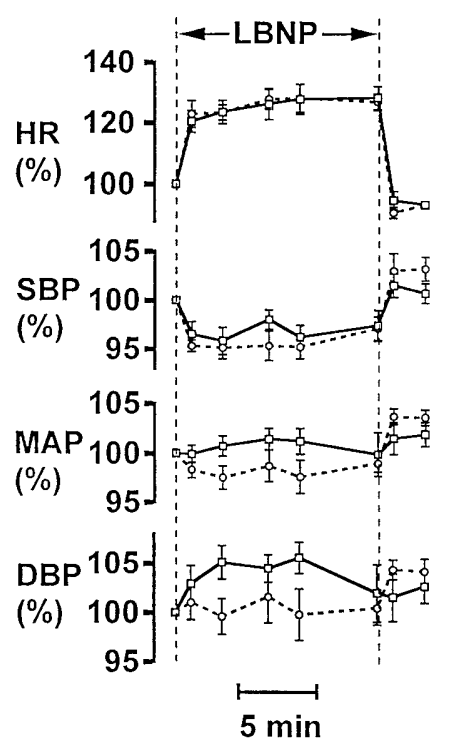

Fig. 1. Heart rate (HR), systolic blood pressure (SBP), mean arterial pressure (MAP) and diastolic blood pressure (DBP) in percent of resting values in Type I diabetic patients (broken line) and control subjects (solid line), during hypovolaemic circulatory stress caused by LBNP of $60 \mathrm{~cm} \mathrm{H}_{2} \mathrm{O}$. No difference in haemodynamic compensatory reactions was seen between the groups 


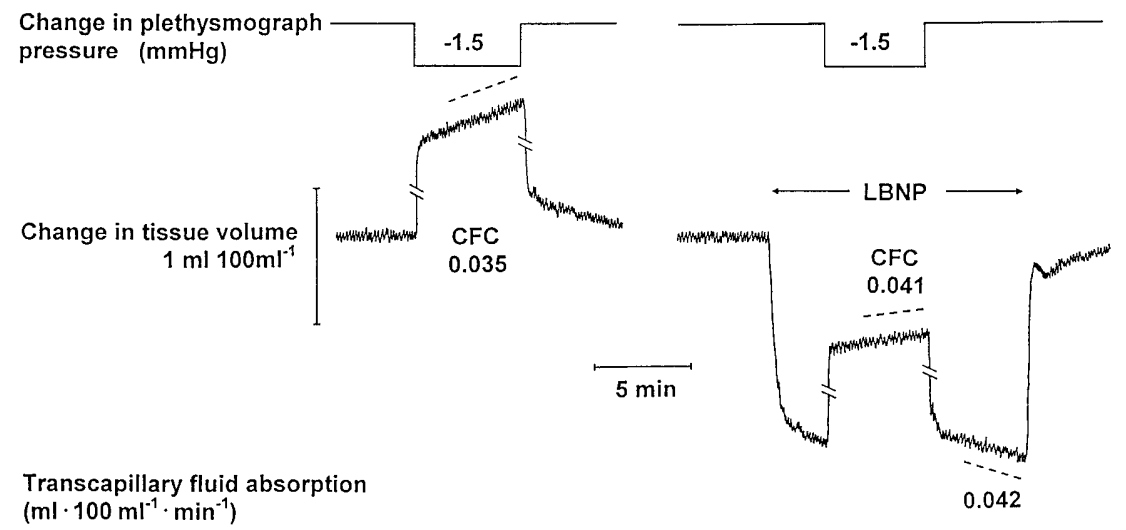

Fig. 2. Left shows an original tracing of tissue volume changes in the upper arm during a recording of $\mathrm{CFC}_{\mathrm{C}}$ in a 23 -year-old diabetic patient by application of $1.5 \mathrm{mmHg}$ external negative pressure. The negative pressure causes a slow volume increase reflecting fluid filtration from blood to tissue. The $\mathrm{CFC}_{\mathrm{C}}$ was $0.035 \mathrm{ml} \cdot 100 \mathrm{ml}^{-1} \cdot \mathrm{min}^{-1} \cdot \mathrm{mmHg}^{-1}$. Right shows a recording of $\mathrm{CFC}_{\mathrm{LBNB}}$ during hypovolaemic circulatory stress caused by a LBNP of $60 \mathrm{~cm} \mathrm{H}_{2} \mathrm{O}$, in the same patient. The transcapillary fluid absorption induced by LBNP was $0.042 \mathrm{ml} \cdot 100 \mathrm{ml}^{-1}$. $\mathrm{min}^{-1}$ and $\mathrm{CFC}_{\mathrm{LBNP}}$ was $0.041 \mathrm{ml} \cdot 100 \mathrm{ml}^{-1} \cdot \mathrm{min}^{-1} \cdot \mathrm{mmHg}^{-1}$. Thus, $\mathrm{CFC}_{\mathrm{LBNP}}$ increased about $20 \%$, compared to the resting value during LBNP. Note that the transcapillary fluid absorption evoked by LBNP was reversed to a net fluid filtration during the CFC manoeuvre, implying that the driving force for fluid absorption was smaller than the magnitude of the applied decrease in external pressure

larger that in the control state. When dividing the transcapillary fluid absorption slope $(0.042 \mathrm{ml}$ $\left.\cdot 100 \mathrm{ml}^{-1} \cdot \mathrm{min}^{-1}\right)$ by $\mathrm{CFC}_{\mathrm{LBNP}}\left(0.041 \mathrm{ml} \cdot 100 \mathrm{ml}^{-1}\right.$ $\left.\cdot \mathrm{min}^{-1} \cdot \mathrm{mmHg}^{-1}\right)$, the driving force for fluid transfer is found to be $1.02 \mathrm{mmHg}$. It is easily seen that the established driving force for fluid absorption must have

Fig. 3. $\mathbf{A} \mathrm{CFC}_{\mathrm{C}}$ in the upper arm of diabetic and control subjects. CFC is reduced by $35 \%$ in the diabetic patients $(* p<0.05)$. B $\mathrm{CFC}_{\mathrm{LBNP}}$ during concomitant hypovolaemic circulatory stress in diabetic and control subjects. This shows that $\mathrm{CFC}_{\mathrm{LBNP}}$ has increased by $35 \%$ in both groups and that $\mathrm{CFC}$ still is decreased in the diabetic compared with control subjects $(* * p<0.01)$. C show, the induced driving force for fluid transfer caused by hypovolaemic circulatory stress. This was similar in diabetic and control subjects been smaller than the applied decrease in plethysmograph pressure because the transcapillary fluid absorption slope was reversed to a net fluid filtration during the $\mathrm{CFC}_{\mathrm{LBNP}}$ manoeuvre.

The capacitance response (mobilisation of peripheral blood to the central circulation) from the upper arm in diabetic and control subjects during LBNP was similar $\left[1.31 \pm 0.10 \mathrm{vs} 1.31 \pm 0.08 \mathrm{ml} \cdot 100 \mathrm{ml}^{-1}\right.$, respectively (NS)].

The $\mathrm{CFC}_{\mathrm{C}}$ in the upper arm of diabetic subjects was decreased compared with control subjects $\left[0.033 \pm 0.003\right.$ vs $0.051 \pm 0.007 \mathrm{ml} \cdot 100 \mathrm{ml}^{-1} \cdot \mathrm{min}^{-1}$ $\cdot \mathrm{mmHg}^{-1}$ respectively $\left.(p<0.05)\right]$ and $\mathrm{CFC}_{\mathrm{LBNP}}$ during LBNP-induced hypovolaemic circulatory stress increased about $35 \%$ compared with the $\mathrm{CFC}_{\mathrm{C}}$ in the control subjects $(p<0.05)$ (Fig. 3). The increase was similar in the diabetic patients, although it failed to reach significance. Thus, as in the resting state $\mathrm{CFC}_{\mathrm{LBNP}}$ was decreased in the diabetic patients $\left[0.046 \pm 0.004\right.$ vs $0.069 \pm 0.006 \mathrm{ml} \cdot 100 \mathrm{ml}^{-1} \cdot \mathrm{min}^{-1}$ $\left.\cdot \mathrm{mmHg}^{-1}(p<0.01)\right]$. The driving force calculated during LBNP-induced hypovolaemic circulatory stress was similar in diabetic and control subjects, $[1.37 \pm 0.11$ vs $1.30 \pm 0.15 \mathrm{mmHg}$, respectively (NS)] (Fig. 3).

In the diabetic patients both $\mathrm{CFC}_{\mathrm{C}}$ and $\mathrm{CFC}_{\mathrm{LBNP}}$ correlated to $\mathrm{HbA}_{1 \mathrm{c}}(\mathrm{r}=0.67, p<0.05$ and $r=0.71$, $p<0.05$, respectively). There was no correlation between CFC and the prevailing blood glucose or disease duration.

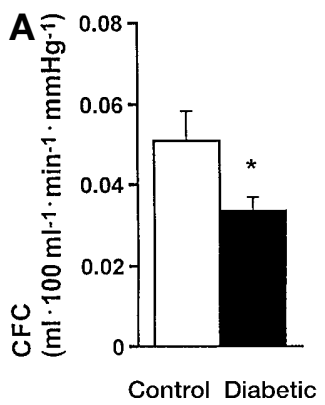

Control Diabetic
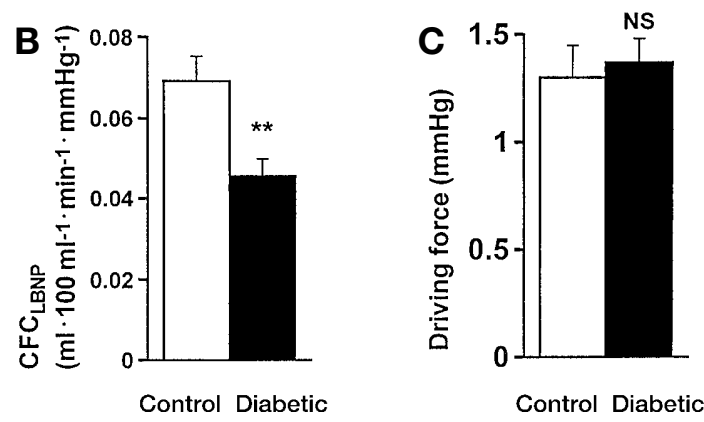


\section{Discussion}

Earlier studies have shown that extravascular fluid passes into the blood during hypovolaemic circulatory stress and this occurs predominantly in skeletal muscle and in the skin, i.e. tissues which contain a large fluid reservoir [2,15]. The driving force for the fluid is established by a decline in capillary hydrostatic pressure induced by reflex autonomic adjustments of the precapillary to postcapillary resistance ratio [15]. Such an alteration of the resistance distribution seems to be linked to activation of $\alpha$-adrenergic and $\beta$-adrenergic receptors in the vascular bed [5]. In humans this transcapillary fluid absorption seems to be larger than in animals [21] probably because of CFC in these tissues is high $[3,22]$. We have recently shown that patients with Type I diabetes have a reduced transcapillary fluid absorption during hypovolaemic circulatory stress before microvascular complications are clinically overt [1]. A possible pathophysiological explanation for the reduced fluid absorption in diabetic subjects could be linked to either a decrease in CFC, a defect establishment of a transcapillary driving force (reduction in capillary pressure) responsible for fluid absorption during hypovolaemia, or a combination of both.

The CFC calculations in this study were based on a transmural pressure gradient caused by a decrease in extravascular pressure instead of the more commonly used increase in intravascular pressure. The negative external pressure applied around the upper arm is fully transmitted to the tissue irrespective of tissue depth and therefore induces a defined increase in capillary transmural pressure [13]. Further, venous pressure and, thus, perfusion pressure is unchanged minimising the influence on the microcirculation [10]. The application of a small increase in transmural pressure gradient avoids activation of local myogenic as well as axon reflex responses, with closure of precapillary sphincters as seen during larger increases in transmural pressure $[10,11,22]$. These protective reflexes might explain the different CFC values found when different methodology has been used $[8,9,22]$.

When the transcapillary fluid filtration in response to an increase in transmural pressure is studied, it is of fundamental importance to be able to separate the capacitance response from the capillary filtration. This is aided by the capacitance response being a rapid process, whereas the capillary filtration is fairly slow. The duration of the capacitance response after a large increase in venous pressure $(\approx 40 \mathrm{mmHg})$ is about $3 \mathrm{~min}[18,23]$. This gradually diminishes when lower increases in pressures are applied and the time for completion of the capacitance response has been found to be well below $2 \mathrm{~min}$ when an increase in transmural pressure of $10 \mathrm{mmHg}$ or less is applied [23]. Furthermore, the duration of the capacitance response is shorter when tissue pressure is reduced compared with methods using venous stasis [24]. Thus, the capacitance response induced by application of $1-2 \mathrm{mmHg}$ external negative pressure ends within $1 \mathrm{~min}$ [25]. Accordingly, the calculation of $\mathrm{CFC}$ between 2 and $5 \mathrm{~min}$ after application of the increase of $1-2 \mathrm{mmHg}$ in transmural pressure gradient in our study is justified. The advantages of external negative pressure compared with the venous congestion technique are that transmural microcirculatory pressure changes are defined and independent of the precapillary to postcapillary resistance ratio. Furthermore, there is no influence on the microcirculation because of reduced perfusion pressure.

As indicated by the low resting heart rates, the study was done on subjects with a good physical condition. The CFC in the healthy subjects was of similar magnitude to that found earlier when applying low transmural pressure increase in the microcirculation $[3,22]$. The CFC was reduced by $35 \%$ in the diabetic patients, implying that the capillary surface area available for fluid transfer was reduced. A defective transmission of negative pressure into the tissue in the diabetic patients that would result in a reduction in the estimated value for $\mathrm{CFC}$ is a possible confounding factor. Adequate pressure transmission was, however, supported by the unchanged capacitance response as we saw in the calf. Other factors of importance might be a delayed capacitance response in the diabetic subjects due to impaired vascular reactivity or disturbed mechanical properties of the vascular walls jeopardising the differentiation between the capacitance response and the filtration process $[26,27]$. Furthermore, blood flow heterogeneity with increased numbers of non-perfused capillaries could also result in delayed capacitance in the diabetic patients $[28,29]$. This would, however, result in an underestimation of the difference in CFC. Thus, the conclusion that CFC is decreased in the diabetic patients seems to be valid. There could be several reasons for the decrease. Reduced capillary density in skeletal muscle has been reported in diabetic animals [30]. In Type I diabetic patients the total number of capillaries has been shown to be unchanged but with increased numbers of non-cellular muscle capillaries, indicating loss of capillary function [31,32]. Also capillary flow heterogeneity could decrease the capillary surface area available for fluid transfer [29]. Water passes not only through intercellular clefts but also through endothelial cells with the aid of aquaporin, a membrane-integrated protein and the function of aquaporin could be disturbed by glycation $[33,34]$. Changes in the capillary wall fibre matrix might impede fluid transport and explain the combination of decreased CFC and increased/normal albumin permeability found in diabetic patients [35]. This divergence could also be the result of a loss of the electrostatic barrier that only affects albumin permeability [36]. It seems probable that there are different mech- 
anisms for transcapillary transport of water and for other molecules, therefore, our data cannot be extrapolated to other substances.

Previous studies on CFC in diabetic patients without microvascular complications have shown increased [7] or unchanged CFC [8,9]. The earlier studies in the $1970 \mathrm{~s}[8,9]$ were before $\mathrm{HbA}_{1 \mathrm{c}}$ became available and therefore the metabolic control of the diabetic subject was not known. This might be important because our data show that $\mathrm{HbA}_{1 \mathrm{c}}$ affects CFC, in line with the finding of increasing $\mathrm{CFC}$ in diabetic patients during pronounced hyperglycaemia [37]. The explanation for this relation could be an increase in the activity of protein kinase $\mathrm{C}$ and vascular endothelial growth factor due to hyperglycaemia with an increase in vascular permeability $[38,39]$. In the earlier studies hyperglycaemic periods before the examination might have increased CFC. The later study in 1993 [7] using the venous congestion technique found no correlation between $\mathrm{CFC}$ and the prevailing bloodglucose or $\mathrm{HbA}_{1 \mathrm{c}}$. The increase in venous pressure was not measured, however, which might influence the estimation of CFC. In all three studies, CFC was measured by application of high transmural pressures, which might elicit myogenic and venoarterial reflexes [10,11]. This might lead to an overestimation of CFC because defective microvascular reflexes have been reported in diabetic patients [40]. This might also influence CFC values found in diabetic patients with microvascular complications where CFC has been found to be increased compared with healthy volunteers $[8,9]$. The effect of diabetes duration itself on CFC has not been fully explained, although no correlation was seen in the later study [7] as well as in ours.

The $\mathrm{CFC}_{\mathrm{LBNP}}$ increased $35 \%$ during hypovolaemic circulatory stress both in controls and diabetic subjects. This probably reflects a more effective perfusion of the capillary bed due to opening of precapillary sphincters $[3,4]$. That the applied decrease in tissue pressure during the $\mathrm{CFC}_{\mathrm{LBNP}}$ manoeuvre in most cases counteracted and even reversed the net fluid absorption indicates that it was higher than the established transcapillary driving force for fluid absorption from tissue to blood. We found that the established driving force over the capillary walls responsible for the transcapillary fluid absorption during LBNP in healthy controls was about $1.3 \mathrm{mmHg}$, which is similar to that described earlier [3] and that in diabetic patients it was unchanged. Studies on the regulation of skin capillary pressure have shown increased capillary pressure in diabetic patients indicating reduced precapillary resistance [6]. The cardiovascular response we found, including the increase in CFC as well as the transcapillary driving force during LBNP-induced sympathetic activation, indicated that the sympathetic vascular regulation was preserved. A sympathetic denervation might, however, still be of importance. That no such effect was found in the arms does not ex- clude this possibility, because selective defects have been shown in legs in early Type I diabetes [41].

The LBNP of $60 \mathrm{~cm} \mathrm{H}_{2} \mathrm{O}$ induced high increases in vascular transmural pressure in legs with a concomitant capacitance response as well as transcapillary filtration. Assuming an $80 \%$ transmission of negative pressure [17], CFC was about $0.003 \mathrm{ml} \cdot 100 \mathrm{ml}^{-1}$ $\cdot \mathrm{min}^{-1} \cdot \mathrm{mmHg}^{-1}$ and similar to that in previous studies where high increases in transmural pressure have been applied $[8,9]$. The CFC calculated for calves was not, however, decreased in diabetic patients contrary to that from the arms that had a small increase in the vascular transmural pressure gradient. Although this might indicate a defect myogenic reactivity in the diabetic patients it is difficult to draw conclusions from these data because the combined effects of increased sympathetic discharge and local protective reflexes on CFC are not known.

The CFC in Type I diabetic patients is reduced by approximately a third compared with control subjects at rest and also during sympathetic stimulation caused by LBNP-induced hypovolaemic circulatory stress. The established driving force for fluid transfer over the capillary walls during hypovolaemia is, however, of similar magnitude in diabetic and healthy control subjects, indicating sympathetic $\alpha$-mediated and $\beta$-mediated microcirculatory control is preserved. The reduced CFC in Type I diabetic patients seems to explain the reduction in transcapillary fluid absorption during hypovolaemia found earlier [1]. Impaired plasma volume regulation has several important clinical implications, such as reduced tolerance to hypovolaemic circulatory stress, e.g. bleeding, rapid gastrointestinal fluid losses or burn injuries, and might contribute to the increased cardiovascular morbidity in Type I diabetic patients.

Acknowledgements. This study was supported by grants from the Novo Foundation Denmark, the Medical Faculty of Lund University, the Medical Research Council (no. 12661), the Swedish Heart-Lung Foundation and the Funds of Malmö University Hospital.

\section{References}

1. Olsen H, Länne T (1999) Reduced transcapillary fluid absorption from skeletal muscle and skin during hypovolemia in insulin-dependent diabetes mellitus. J Intern Med 246: 477-488

2. Hall EH, Schwinghamer JM, Lalone B (1976) Mechanism of blood vessel constriction during hemorrhage. Am J Physiol 230: 569-578

3. Länne T, Edfeldt H, Quittenbaum S, Lundvall J (1992) Large capillary fluid permeability in skeletal muscle and skin in man as a basis for rapid beneficial fluid transfer between tissue and blood. Acta Physiol Scand 146: 313-319

4. Mellander S, Lewis D (1963) Effect of hemorrhagic shock on the reactivity of resistance and capacitance vessels and on capillary filtration transfer in cat skeletal muscle. Circ Res 13: 105-118 


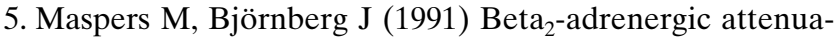
tion of capillary pressure autoregulation during haemorrhagic hypotension, a mechanism promoting transcapillary fluid absorption in skeletal muscle. Acta Physiol Scand 142: 470-475

6. Sandeman DD, Shore AC, Tooke JE (1992) Relation of skin capillary pressure in patients with insulin-dependent diabetes mellitus to complications and metabolic control. N Engl J Med 327: 760-764

7. Jaap AJ, Shore AC, Gartside IB, Gamble J, Tooke JE (1993) Increased microvascular fluid permeability in young Type I (insulin-dependent) diabetic patients. Diabetologia 36: 648-652

8. Poulsen HL, Nielsen SL (1976) Water filtration in shortand long-term diabetes mellitus. Diabetologia 12: 437-440

9. Alpert JS, Coffmann JD, Balodimos MC, Koncz L, Soeldner JS (1972) Capillary permeability and blood flow in skeletal muscle of patients with diabetes mellitus and genetic prediabetes. N Engl J Med 9: 454-460

10. Lundvall J (1989) Myogenic mechanism in the control of systemic resistance and transcapillary fluid exchange in man. J Hypertens [Suppl 4]: S85-S91

11. Henriksen O (1976) Local nervous mechanism in regulation of blood flow in human subcutaneous adipose tissue. Acta Physiol Scand 97: 385-391

12. Wolthius RA, Bergman SA, Nicogossian AE (1974) Physiological effects of locally applied reduced pressure in man. Physiol Rev 54: 566-595

13. Lundvall J, Länne T (1989) Transmission of externally applied negative pressure to the underlying tissue. A study on the upper arm of man. Acta Physiol Scand 136: 403-409

14. Åblad B, Mellander S (1963) Comparative effects of hydralazine, sodium nitrite and acetylcholine on resistance and capacitance blood vessels and capillary filtration in skeletal muscle in the cat. Acta Physiol Scand 58: 319-329

15. Mellander S (1960) Comparative studies of the adrenergic neuro-hormonal control of resistance and capacitance blood vessels in the cat. Acta Physiol Scand 50[Suppl 176]: $1-86$

16. Lundvall J, Länne T (1989) Large capacity in man for effective plasma volume control in hypovolemia via fluid transfer from tissue to blood. Acta Physiol Scand 137: 513-520

17. Olsen H, Länne T (1998) Reduced venous compliance in the lower limbs of ageing man and its importance for capacitance function. Am J Physiol 275: H878-H886

18. Schnizer W, Klatt J, Baeker H, Reickert H (1978) Comparison of scintigraphic and plethysmographic measurements for determination of capillary filtration coefficient in human limbs. Basic Res Cardiol 73: 77-84

19. Hafferl, A (1957) Lehrbuch der topographischen Anatomie. Springer Verlag, Berlin Göttingen

20. Cooper KE, Edholm OG, Mottram RF (1955) The blood flow in skin and muscle of the human forearm. J Physiol (Lond) 128: 258-267

21. Länne T, Lundvall J (1989) Very rapid net transcapillary fluid absorption from skeletal muscle and skin in man during pronounced hypovolemic circulatory stress. Acta Physiol Scand 136: 1-6

22. Lundvall J, Länne T (1989) Much larger transcapillary hydrodynamic conductivity in skeletal muscle and skin of man than previously believed. Acta Physiol Scand 136: 7-16

23. Gamble J, Gartside IB, Christ F (1993) A reassessment of mercury in silastic strain gauge plethysmography for microvascular permeability assessment in man. J Physiol (Lond) 464: 407-422
24. Kongstad L, Grände PO (1998) The capillary filtration coefficient for evaluation of capillary fluid permeability in cat calf muscles. Acta Physiol Scand 164: 201-211

25. Länne T (1989) Fluid transfer from tissue to blood in hypovolemia and its possible importance for plasma volume control. An experimental study in man. [Thesis]. Lund University, Malmö

26. Schaper NC, Houben AJ, Schoon Y, Kooman JP, Huvers FC, Kruseman AC (1994) Venous compliance and the venodilatory effect of nitroglycerin in insulin-dependent diabetic patients with and without (incipient) nephropathy. Eur J Clin Invest 24: 382-387

27. Tooke JE, Lins PE, Östergren J, Fagrell B (1985) Skin microcirculatory autoregulatory responses in type 1 diabetes: the influence of duration and control. Int $\mathbf{J}$ Microcirc Clin Exp 4: 249-256

28. Jörneskog G, Brismar K, Fagrell B (1995) Skin capillary circulation severely impaired in toes of diabetic patients with IDDM, with and without late diabetic complications. Diabetologia 38: 474-480

29. Kindig CA, Sexton WL, Fedde MK, Poole DL (1998) Skeletal muscle microcirculatory structure and hemodynamics in diabetes. Respir Physiol III: 163-175

30. Bohlen HG, Niggl BA (1980) Early arteriolar disturbance following streptozotocin-induced diabetes in adult mice. Microvasc Res 20: 19-29

31. Leinonen H, Matikainen E, Juntunen J (1982) Permeability and morphology of muscle capillaries in Type I (insulindependent) diabetes mellitus. Diabetologia 22: 158-162

32. Tilton RG, Faller AM, Burkhart JK, Hoffman PL, Kilo C, Williamson JR (1985) Pericyt degeneration and acellular capillaries are increased in the feet of human diabetic patients. Diabetologia 28: 895-900

33. Michell CC, Curry FE (1999) Microvascular permeability. Physiol Rev 79: 703-761

34. Nielsen S, Smith BL, Christensen EI, Agree P (1993) Distribution of the aquaporin CHIP in secretory and resorptive epithelia and capillary epithelia. Proc Natl Acad Sci USA 90: 7275-7279

35. Katz MA (1992) Structural change in fiber matrix allows for enhanced permeability and reduced hydraulic conductivity. Microvasc Res 43: 1-6

36. Bendt-Hansen L, Feldt-Rasmussen B, Kverneland A, Deckert T (1993) Plasma disappearance of glycated and non-glycated albumin in Type I (insulin-dependent) diabetes mellitus: evidence for charge dependent alterations of the plasma to lymph pathway. Diabetologia 36: 361-363

37. Parving HH, Noer I, Deckert T et al. (1976) The effect of metabolic regulation on microvascular permeability to small and large molecules in short-term diabetics. Diabetologia 12: 161-166

38. Tilton RG, Kawamura T, Chang KC et al (1997) Vascular dysfunction induced by elevated glucose levels in rats is mediated by vascular endothelial growth factor. J Clin Invest 99: 2192-2202

39. Koya D, King GL (1998) Protein kinase C activation and the development of diabetic complications. Diabetes 47: 859-866

40. Shore AC, Price KJ, Sandeman DD, Tripp JH, Tooke JE (1994) Posturally induced vasoconstriction in diabetes mellitus. Arch Dis Child 70: 22-23

41. Gilmore JE, Allen JA, Hayes JR (1990) A comparison of peripheral vasoconstrictor responses and cardiovascular autonomic function tests in diabetic patients. Diabetologia 33: $350-356$ 